\title{
A Study of Prevalence of Asymptomatic Spontaneous Bacterial Peritonitis in Cirrhotic Patients with Ascites
}

\author{
Dr. V. Uvaraj Muruganandam¹, Dr. P. S. Manshur ${ }^{2}$ \\ ${ }^{1,2}$ Senior Assistant Professor, Department of General Medicine, Coimbatore Medical College Hospital, Tamilnadu, India
}

\begin{abstract}
Objectives: To detect the prevalence of asymptomatic Spontaneous Bacterial Peritonitis in Cirrhotic patients with ascites and treat them prior to complication. Study design: Observation study. Place and duration of study: Coimbatore medical college hospital, from July 2014 to July 2015. Methodology: consecutive patients admitted with ascites in the medical and gastroenterology wards for ascites. Results: Of the 50 patients, only 8 of the patients were found to have SBP (16\%). Among the study members, about $40 \%$ were non alcoholics and $60 \%$ were alcoholics. 60\% of my study population had cirrhosis for more than 5 years and $40 \%$ had cirrhosis for less than 5 years. The ascitic fluid analysis was like only around 5 of the population had cells more than 250 / cu.mm. Culture study trend was like around $12 \%$ of the patients were culture positive. Among the organisms studied, the majority was E. coli and the others were Streptococcus and Klebsiella. The Child Pugh scoring was calculated as per the criteria mentioned earlier and the majority came under Class B, followed by Class $A$ and the least by Class $C$. There is a correlation between the ascitic fluid and the incidence of SBP. A low protein level of less than $1 \mathrm{~g} / \mathrm{dl}$ has strong predilection for contracting SBP. The ascitic fluid protein level was correlated with the incidence of SBP and it was also found significant at $p<0.05$. Conclusion: Prevalence of asymptomatic SBP is very low at $16 \%$. There is also a strong correlation between low ascitic fluid protein level $(<1 \mathrm{~g} / \mathrm{dl})$ and $S B P$.
\end{abstract}

Keywords: cirrhosis, spontaneous bacterial peritonitis, ascites

\section{Introduction}

Spontaneous bacterial peritonitis (SBP) is one the most common and life-threatening complication of cirrhosis. The term spontaneous bacterial peritonitis (SBP) was coined by Conn in 1971to describe the infection of ascitic fluid in the absence of any intra-abdominal, surgically treated source of infection. ${ }^{[1]}$ Mortality rates have stayed constant in spite of the development of new antibiotic treatments and early diagnosis of SBP infection. Recent British Society of Gastroenterology (BSG) guidelines on the management of ascites cirrhosis highlight the effect of early diagnosis and prompt treatment with the reduction of in-hospital mortality from $90 \%$ to less than $20 \%{ }^{[2][3]}$

Bacterial translocation in the "passage" of bacteria from the lumen to the mesenteric lymph nodes and thereafter to the blood stream and other extra-intestinal sites. It is considered to be the key step in the pathogenesis of SBP. Today, even with intensive treatment, the in-hospital mortality is still between $10 \%$ and $30 \%$. Among the patients about 10 to $32 \%$ are asymptomatic. ${ }^{[8]}$ The cause of asymptomatic cases is mainly due to genetic makeup of different people.SBP was diagnosed using standard criteria, namely, an absolute neutrophil count of 250 cells $/ \mathrm{mm} 3 .^{[5][6]}$ It can either be culture positive or culture negative. If ascitic fluid cultures were negative in the presence of neutrocytic ascites, these patients were characterized as having culture-negative neutrocytic ascites (CNNA). [7] [10] Patients with positive cultures on ascetic fluid but without neutrocytic ascites were classified as having bacterascites.

\section{Materials and Methods}

Subjects were selected from the patients getting admitted in the medical and gastroenterology ward during the period of
July 2014 to July 2015 at Coimbatore Medical College. Patients with Ascites and those who have undergone ultrasound scan and proven cirrhosis are selected for the study. After that a fresh ultrasound is also done to rule out any active infection and other clinical conditions that can interfere with the exclusion criteria like pancreatitis. To exclude the possibility that any of the patients may have had symptoms of SBP or were at risk for SBP, the patient should not be on prophylactic antibiotics, have no history of fever in the past two weeks, no features of hepatic encephalopathy, no features suggestive of pre existing intra abdominal infection and no features suggestive of renal failure. After taking informed consent $10 \mathrm{ml}$ of ascitic fluid is collected and sent for various biochemical analysis like proteins and sugar along with cell count.

The cell count is measured by Nubauer's chamber. Equal quantity of ascitic fluid and Turk's WBC solution is mixed and kept aside for 10 mins. Then the solution is put in the chamber and it is visualized under high power. 10 high power fields are observed and the count is taken. The count multiplied by 40 is taken as the count in 1 cu.mm.

Another $10 \mathrm{ml}$ was taken and sent for culture and inoculated into culture tubes under aseptic precaution. Initially the fluid is made into smears and gram staining is done. Later on the fluid is inoculated into three culture media which are;

1. Nutrient agar slope

2. Blood agar to

3. McConkey agar

Each of the above given culture study is incubated for 24 hours at $37^{\circ} \mathrm{C}$. After that the corresponding colonies that show the response is segregated to identify the organism Along with it a liver function test, serum amylase and 


\section{International Journal of Science and Research (IJSR) \\ ISSN (Online): 2319-7064}

Index Copernicus Value (2013): 6.14 | Impact Factor (2015): 6.391

prothrombin time is also done. To avoid person to person error the same person has to collect the asciticfluid. It is also sent to the same lab. Soon after the procedure, a prophylactic antibiotic course is started. With the parameters, the Child's Tourette Pugh scoring is also done.

\section{Observation and Results}

The study population consisted of 50 patients who had full filled the inclusion and exclusion criteria. Retrospectively, the duration of cirrhosis was also noted. After taking a fresh USG abdomen, the ascitic fluid analysis was sent as decided in the methodology. Among the study members, about $40 \%$ were non alcoholics and $60 \%$ were alcoholics. $60 \%$ of my study population had cirrhosis for more than 5 years and 40 $\%$ had cirrhosis for less than 5 years. The ascitic fluid analysis was like only around 5 of the population had cells more than 250 / cu.mm. Culture study trend was like around $12 \%$ of the patients were culture positive. Among the organisms studied, the majority was E. coli and the others were Streptococcus and Klebsiella

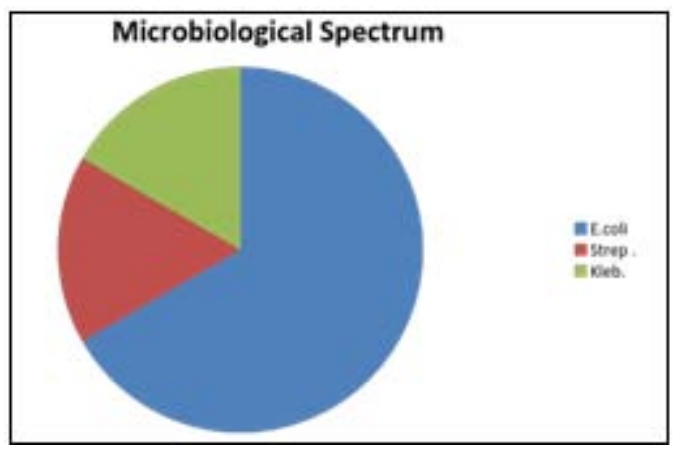

Among the 50 patients, only 8 of the patients were found to have SBP. It was decided either with a total cell count of more than 250 / cu.mm or with a culture positive study. So the calculated prevalence was $\mathbf{1 6} \%$. The Child Pugh scoring was calculated as per the criteria mentioned earlier and the majority came under Class B, followed by Class A and the least by Class $\mathrm{C}$

\begin{tabular}{|c|c|c|c|}
\hline $\begin{array}{c}\text { Child Pugh } \\
\text { scoring }\end{array}$ & $\begin{array}{c}\text { Culture alone } \\
\text { Positive }\end{array}$ & Cell count & Both \\
\hline Class C & 2 & 0 & 1 \\
\hline Class A \& B & 1 & 2 & 2 \\
\hline
\end{tabular}

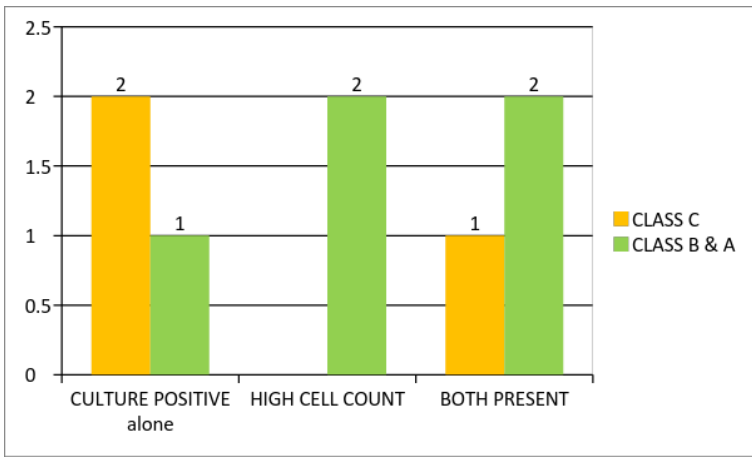

There is a correlation between the ascitic fluid and the incidence of SBP. A low protein level of less than $1 \mathrm{~g} / \mathrm{dl}$ has strong predilection for contracting SBP. Theascitic fluid protein level was correlated with the incidence of SBP and it was also found significant at $\mathrm{p}<0.05$.

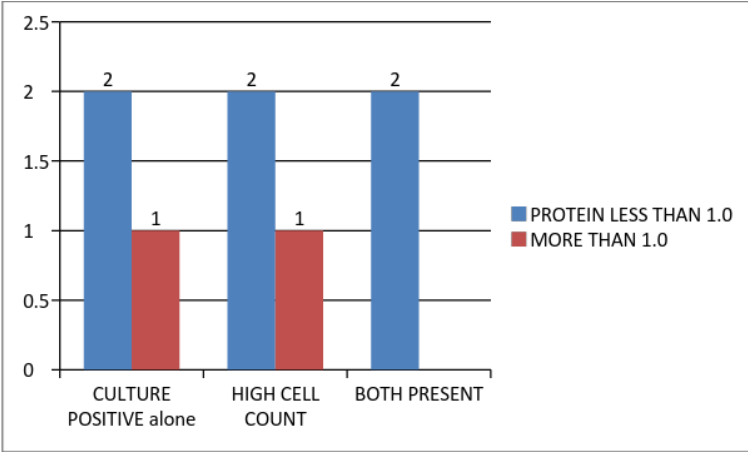

The disease severity determined by Child Pugh score has a correlation in a way that a higher score ie class $\mathrm{C}$ has increased chance to succumb to SBP. After calculating the co relation between the child pugh classification and the prevalence of SBP it was found to be significant at $p<0.05$

\section{Discussion}

Spontaneous Bacterial Peritonitis is a life threatening complication that is characterized by an infection of the ascitic fluid in the absence of any foci of inflammation. So a prompt diagnosis of the disease is very necessary as the mortality of the disease is very high if not intervened at the right time. The study conducted at Coimbatore Medical College regarding the prevalence of Asymptomatic Spontaneous Bacterial Peritonitis was done for a period of 1 year. 50 cases were selected according to the inclusion and exclusion criteria. The samples were analysed with strict confidentiality and the results were also considered the same.

Among the patients studied, majority of the study population were consisting of males. Also it was found that the around $60 \%$ of the study population were alcoholics irrespective of the sex. The duration of cirrhosis was also varying and as the charts shown above, the duration of the cirrhosis has no correlation to the occurrence of SBP. With respect to the cell count, only 5 of the study population had a count of more than 250 /cu.mm. The highest value recorded among the study population was $600 /$ cu.mm. The lowest was recorded as 2 cells. So, only $10 \%$ of the patients had Culture Negative Neutrocytic Ascites (CNNA). The culture study trend showed that majority were gram negative bacilli, E.coli being the most common seen on 4 out of the 6 culture positive analysis. The other two were Klebsiella pneumonia and Streptoccocus. As the case defining criteria was fulfilment of any one ie cell count more than 250 /cu.mm or culture positivity, 8 cases fulfilled the criteria and so the prevalence of Asymptomatic SBP was as low as 16 $\%$.Patients coagulation status was also judged by analysing the prothrombin time. With the multiple parameters, a The Child pughs criterion was calculated and the patients were classified. Majority of the cases came in the Class B with 32 patients. Class A was occupied by 13 patients and Class $\mathrm{C}$ by 5 patients. The bilirubin levels were found to be almost equally distributed with 29 patients showing hyperbilirubinemia and 21 patients with normal bilirubin levels next some other parameters were correlated. Firstly as

\section{Volume 5 Issue 8, August 2016}




\section{International Journal of Science and Research (IJSR) \\ ISSN (Online): 2319-7064}

Index Copernicus Value (2013): 6.14 | Impact Factor (2015): 6.391

mentioned in the literatures, the ascitic fluid protein level has a strong predilection for contracting infection due to the decreased action of the reticuloendithelal system and the reduced opsonin level in the fluid. In our study, by correlating using the Chi- square technique, the correlation was significant at $\mathrm{p}<0.05$

In the study, it was found that among the 8 positive for SBP 5 had protein level less than $1 \mathrm{~g} / \mathrm{dl}$. So comparing with the protein level of non SBP cases, the values were significant and hence considered to be having a positive correlation. Next to be considered was the Child Pugh's score and its correlation with SBP. As mentioned in various literatures, the severity of Child Pugh's score has a strong predilection in formation and worsening of SBP. In our study the number of cases with Child Pugh's score as Class $\mathrm{C}$ were 5.Among the 8 who had SBP, 3 were in Class $C$ prognostic index and thereby was significant at $p$ value less than 0.05 . The $60 \%$ of the population who were alcoholics had not abstained from alcohol. But there was no significant link between the pathogenesis or rather the occurrence of SBP as the non SBP group also was having a lot of alcoholics. Alcoholism per se do not aggravate the risk of developing SBP. But following a bout of alcohol, severe retching leading to Mallory Weiss tear or a bout of hematemesis can lead to SBP. Also complication i.e aspiration pneumonia can precipitate SBP. High bilirubin notes in roughly $60 \%$ of the patients had no direct impact on the load of SBP as the hyperbilirubinemia was found in more number in patients without SBP too and hence proven to be not significant. But it has an indirect correlation as it has been incorporated into the Child pugh"s criteria. To rule out other causes of infection, serum amylase levels were studied in all the cases. But the level was minimal and it had no direct link or its raised value does not point towards SBP. Now taking into consideration about the individual case of SBP i.e. ones with cell count more than 250 and those with culture, some more deductions were made

In correlation to the protein level in asciticfluid, when taking culture alone 2 of the 3 patients were having it less than 1 $\mathrm{g} / \mathrm{dl}$. But when cell count is taken, 2 of the 3 patients were having it less than $1 \mathrm{~g} / \mathrm{dl}$. When both are positive, all the 2 had protein less than $1 \mathrm{~g} / \mathrm{dl}$. Next in line is the Child Pugh's Classification. Among the culture positive, 2 out of 3 were in Class $\mathrm{C}$. In the cell count criteria none were in class $\mathrm{C}$ but when combined 1 out of the 3 were in Class C. Bilirubin study revealed that all the 3 of the culture positive patients were having bilirubin more than 1, high cell count 1 out of 3 were showing high bilirubin and when both are positive 1 out of 2 were having hyperbilirubinemia. Alcoholism and correlation with the SBP variants were as follows. All the culture positive patients were alcoholic, 1 of the 2 high cell count variant was an alcoholic and when combined again all of them were alcoholics

\section{Conclusion}

The study regarding the prevalence of Asymptomatic Spontaneous Bacterial Peritonitis was conducted during the period of July 2014 to July 2015. The ascitic fluids were examined and the results were analyzed. After the analysis, we have come to a conclusion that the prevalence of SBP is very low at $\mathbf{1 6 \%}$. There is also a strong correlation between low ascitic fluid protein level $(<1 \mathrm{~g} / \mathrm{dl})$ and SBP. Among the study population, the majority of the patients with SBP had Child Pugh's criteria in Class C. This was also correlated well in our study. So to conclude, the prevalence of Asymptomatic Spontaneous Bacterial Peritonitis was very low in our study conducted at Coimbatore medical college

\section{References}

[1] Rimola A, Garcia-Tsao G, Navasa M et al. Diagnosis, treatment and prophylaxis of spontaneous bacterial peritonitis: a consensus document. J Hepatol 2000;32:142-153

[2] Garcia-Tsao G. Current management of the complication of cirrhosis and portal hypertension: varicealhemorrhage, ascites and spontaneous bacterial peritonitis. Gastroenterology 2001; 120:726-748

[3] Conn HO, Fessel JM. Spontaneous bacterial peritonitis in cirrhosis: variations on a theme. Medicine 1971 ; 50:161-197

[4] Runyon BA. Early events in spontaneous bacterial peritonitis. Gut 2004; 53:782-784.

[5] Runyon BA. Low-protein-concentration ascetic fluid is predisposed to spontaneous bacterial peritonitis. Gastroenterology 1986;91:1343-1346.

[6] Rimolo A, Garcia-Tsoa G, Navasa M PiddockLJ, PlanasR, Bernard B, Inadomi JM. Diagnosis, Treatment and prophylaxis of spontaneous bacterial peritonitis: a consensous document. International Ascites Club.JHepatol 2000:32:142-153

[7] Kim WR, Brown RS Jr, Terrault NA, El-SeragH.Burden of liver disease in the United States: summary of a workshop.Hepatology 2002;36:227-242

[8] Schiano TD, Kim- Scluger L, Gondolesi G, Miller CM. Adult living donor liver transplantation: the hepatologist's perspective. Hepatology 2001;33:3-9

[9] Castellote J, Lopez C, Gornals J, et al. Rapid diagnosis of spontaneous bacterial peritonitis by use of reagent strips. Hepatology 2003;37:893-896.

[10] WONG f, Bernardi M, Balk R, et al. Sepsis in cirrhosis: report of the $7^{\text {th }}$ meeting of the International Ascites Club.Gut 2005:54:718-725.

[11] Pelletier G, Lesur G, Ink O, Hagege H, Attali P, Buffet $\mathrm{C}$, Etienne J: Asymptomatic bacterascites: IS is spontaneous bacterial peritonitis? Hepatology 1991;14:: $112-115$

[12] Castellote J, Xiol X, Verdauger R, et al. Comparison of two ascetic fluid culture methods in cirrhotic patients with spontaneous bacterial peritonitis. Am J Gastroenterol 1990;85:1605-1608.

[13] Felisart J, RimolaA, Arroyo V, et al. Cefotaxime is more effective than is ampicillin-tobramycin in cirrhotics with severe infections. Hepatology 1985;457462. 